\title{
Theoretical Study of Kaolinite Structure; Energy Minimization and Crystal Properties
}

\author{
Mohamed Salah Karmous \\ Département de physique, Faculté des Sciences de Sfax, \\ Route de la Soukra km 4 - B.P. n 802 - 3038 Sfax, Tunisie \\ E-mail: karmousssalah@yahoo.fr \\ Received April 19, 2011; revised April 25, 2011; accepted May 9, 2011
}

\begin{abstract}
Computational energy minimization techniques have been used to study the structure and crystal properties of kaolinite. The full elastic tensors of the sheet silicates of clay have been derived with first-principles calculations based on density functional theory. All calculations were performed using GULP program.
\end{abstract}

Keywords: Kaolinite, GULP, Energy, Crystal Properties, Calculation, Elasticity

\section{Introduction}

Molecular modeling methods have been increasingly used in the past decade to simulate a wide range of materials and to evaluate their microscopic structure, physical, and thermodynamic properties. Clays and related layered minerals are fine grained and poorly crystalline materials. Large single crystals of clay minerals suitable for X-ray refinement studies are lacking and therefore only a few detailed structural characterizations exist [1-4]. Clay minerals also possess low crystal symmetry and have a unique chemistry that is characterized by a variety of multicomponent substitutions in the tetrahedral and octahedral sheets. Depending upon the type of structural substitution and net charge, the clay may become expandable and provide a suitable host for a variety of intercalates.

Molecular computer simulations have become extremely helpful in providing an atomistic perspective on the structure and behavior of clay minerals.

In other hand elastic properties of clay minerals are almost unknown, mainly because of the difficulty presented by the intrinsic properties. Their small grain size makes it is impossible to isolate an individual crystal of clay large enough to measure acoustic properties [5]. So far the effective elastic properties of clays have been derived either by theoretical computation [6-8], by a combination of theoretical and experimental investigations on clay-epoxy mixture [9] or by empirical extrapolations from measurements on shales [10-12]. These derived values of clay moduli show little agreement.
Kaolinite is a 1:1 layer clay composed of a repeating layer of an aluminum octahedral (O) sheet and a silicon tetrahedral $(\mathrm{T})$ sheet. Interlayer hydroxyl groups extend from the octahedral sheet into the interlayer region where they form hydrogen bonds to basal oxygens of the opposing tetrahedral silicate sheet [13] (Figure 1).

In this paper a tentative of junction between energetic and crystal properties of kaolinite is presented.

\section{Methods}

\subsection{Energy Calculation}

Energy minimizations were carried out using the program GULP [15]. This utilizes interatomic potentials for describing the interactions within the layered silicate structure. The interatomic potentials used are given in Table 1. A shell model [16] is used to describe the polarization of the $\mathrm{O}^{2-}$ ions. All atoms have integral charges except for the $\mathrm{OH}$ groups, whose component atoms have partial charges [17] so as to reproduce the dipole moment of the $\mathrm{OH}$ group [18]. Atom based cut-offs to $12 \AA$ are used for describing the two body short range interactions and a Ewald summation technique is used for the dispersion and electrostatic interactions [19].

\subsection{Simulation Principle}

The potential model describing the effective forces acting between the atoms in the structure has the following 


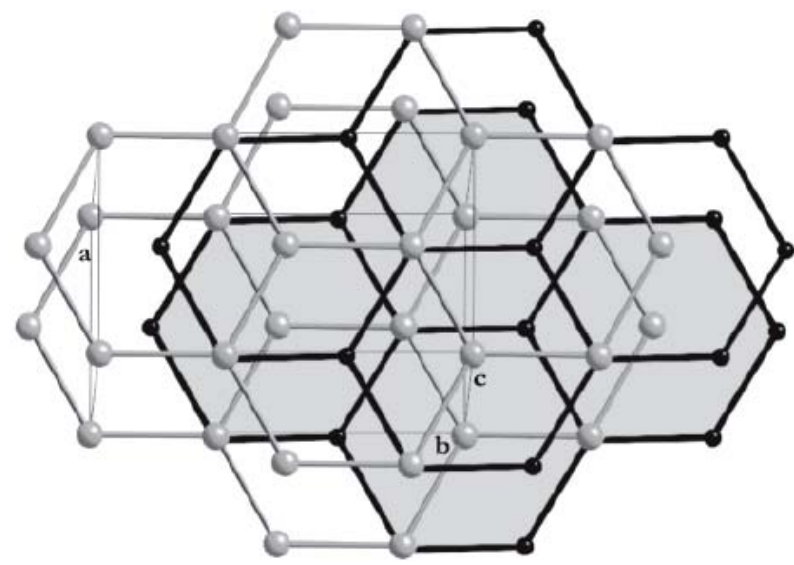

Figure 1. Stacking polytypism in kaolinite; Only the $\mathrm{Si}^{4+}$ ions (dark) and the $\mathrm{Al}^{3+}$ (light) are shown for simplicity. The view direction is perpendicular to the sheets and a shading has been added to the lower $\mathrm{Si}^{4+}$ layer. The thin lines denote the unit cell [14].

components [18].

A two-body short-range term describes repulsions from electron cloud overlap and attractions due to dispersion and covalence. In this study we describe cation-O and the $\mathrm{O}-\mathrm{O}$ interactions using a Buckingham function: $U_{s r}=A \exp (-r / \rho)-C / r^{6}$, where the exponential term describes the repulsive energy and the $r^{6}$ term the longer range attraction. The intramolecular $\mathrm{OH}$ interaction is representedb $y$ a Morse function: $U_{s r}=D\{1-$ $\left.\exp \left[-\beta\left(r-r_{e}\right)\right]\right\}^{2}$, where $r$ and $r$. are the observed and equilibrium interatomic distances, respectively. Coulomb forces are not included between atoms coupled by a Morse potential, as it is assumed that this potential describes all components of the interactions between the two atoms. As in many previous simulation studies on silicates, the short range cation-cation interactions are not significant and were therefore neglected.

A three-body short-range term describes angular dependent covalent forces. A simple approach is to include bond-bending terms about the tetrahedral cation of the type: $U_{t h b}=1 / 2 K_{\text {thb }}\left(\theta-\theta_{0}\right)^{2}$. where $K_{\text {thb }}$ is the harmonic three-body force constant, and $\theta$ and $\theta_{0}$ are the observed and ideal tetrahedral O-T-O bond angles, respectively.

A term to describe electronic polarizability is required if dielectric and dynamic properties are to be modeled accurately. In this study the shell model was used, which provides a simple mechanical model of electronic polarizability. The coreshell self energy is given by $U s=$ $1 / 2 K_{s} r^{2}$ where $K_{s}$ is the harmonic spring constant and $r$ is the core-shell separation.

In Table $\mathbf{1}$ are represented all the potential used during

Table 1. Potential used in simulation.

\begin{tabular}{|c|c|c|c|c|c|c|}
\hline \multicolumn{7}{|c|}{ Two body short range interaction ${ }^{\mathrm{a}}$} \\
\hline Atom 1 & Atom 2 & Potential & $\mathrm{A} / \mathrm{eV}$ & $\rho / \AA$ & $C / \mathrm{eV} \AA^{6}$ & References \\
\hline Al1 c & $\mathrm{O} 1 \mathrm{~s}$ & Buckingham & 1460 & 0.299 & 0.00 & [17] \\
\hline $\mathrm{O} 2 \mathrm{c}$ & Al1 c & Buckingham & 1140 & 0.299 & 0.00 & [17] \\
\hline Si1 c & $\mathrm{O} 1 \mathrm{~s}$ & Buckingham & 1280 & 0.321 & 10.7 & [17] \\
\hline $\mathrm{O} 2 \mathrm{c}$ & Si1 c & Buckingham & 984 & 0.321 & 10.7 & [17] \\
\hline $\mathrm{O} 1 \mathrm{~s}$ & $\mathrm{O} 1 \mathrm{~s}$ & Buckingham & 22800 & 0.149 & 27.9 & [17] \\
\hline $\mathrm{O} 2 \mathrm{c}$ & $\mathrm{O} 1 \mathrm{~s}$ & Buckingham & 22800 & 0.149 & 27.9 & [17] \\
\hline $\mathrm{O} 2 \mathrm{c}$ & $\mathrm{O} 2 \mathrm{c}$ & Buckingham & 22800 & 0.149 & 27.9 & [17] \\
\hline $\mathrm{H} 1 \mathrm{c}$ & $\mathrm{O} 1 \mathrm{~s}$ & Buckingham & 312 & 0.250 & 0.00 & [17] \\
\hline \multicolumn{7}{|c|}{ Morse potential } \\
\hline Atom 1 & Atom 2 & Potential & $D_{\mathrm{e}} / \mathrm{eV}$ & $\beta / \AA^{-1}$ & $r_{\mathrm{e}} / \AA$ & References \\
\hline $\mathrm{H} 1 \mathrm{c}$ & $\mathrm{O} 2 \mathrm{c}$ & Morse-Coulomb & 7.05 & 2.20 & 0.949 & [17] \\
\hline \multicolumn{7}{|c|}{ Shell model interaction } \\
\hline Atom 1 & Atom 2 & Potential & $\mathrm{Ks} / \mathrm{eV} \AA^{-2}$ & & & References \\
\hline $\mathrm{O} 1 \mathrm{c}$ & $\mathrm{O} 1 \mathrm{~s}$ & Spring & 74.90 & & & [17] \\
\hline \multicolumn{7}{|c|}{ Three body interaction } \\
\hline Atom 1 & Atom 2 & Atom3 & $K_{\text {thb }} / \mathrm{eV} \mathrm{rad}^{-2}$ & $\theta /{ }^{\circ}$ & & References \\
\hline Si1 c & $\mathrm{O} 1 \mathrm{~s}$ & $\mathrm{O} 1 \mathrm{~s}$ & 2.097 & 109.470 & & [17] \\
\hline Al1 c & $\mathrm{O} 2 \mathrm{c}$ & $\mathrm{O} 1 \mathrm{~s}$ & 2.097 & 109.470 & & [17] \\
\hline
\end{tabular}


this work.

\subsection{Elastic Constant}

The calculation of elastic constants is potentially very useful, since the full tensor has only been measured experimentally for a very small percentage of all known solids. This is primarily because the practical determination typically requires single crystals with a size of a few micrometers at least.

The elastic constant tensor $\mathrm{C}$, is calculated analytically using standard procedures, which require the prior calculation of the second derivatives of the total lattice energy with respect to the six bulk strain components and with respect to atomic coordinates.

The elastic constants were calculated using GULP program.

\section{Results and Discussion}

In Table 2, energetic simulation of structural properties of kaolinite is presented.

The value of kaolinite total lattice energy obtained is equal to $-827.41650215 \mathrm{eV}$, primitive cell volume is $321.304389 \AA^{3}$. This result is near to energy values found in previous works [20]. The lowest total energy structure obtained from these calculations was that which started from the experimental structures reported by Neder et al. [20] and by Bish [2], i.e., both initial structures yield essentially identical final structures with the same total energy, the same internal bond lengths, and unit cell volumes that differ by only $0.025 \%$ (Table 2), this difference is due to hydroxyl $(\mathrm{OH})$ orientation in interlayer region of kaolinite structure.

Lattice parameters $a$ and $b$ from Sato et al. (2005) [21] are shorter and agree better with experiment than those of the present work, while the opposite is true for the $c$ parameter. This means that our calculations predict a smaller sheet separation, but larger lattice parameters in the planes.

Elastic constant was calculated using structural parameter listed in Table 2, the results are summarized on Table 3, and are compared to many works.

The qualitative study of the table shows:

- C11 C22 >> C33.

- C12 differs significantly from bibliographic value.

- $\mathrm{C} 23 \sim \mathrm{C} 13$

- $\quad$ C15 and C46 is different to zero.

These values of elastic constant reflect the hexagonally symmetric structure.

Differences in other elastic constants are either related to this or the difference of the density value, concentration and arrangement of defects ([14] and [22]).
Table 2. Structural properties derived from simulations of kaolinite.

\begin{tabular}{ccccc}
\hline \multicolumn{5}{c}{ Kaolinite } \\
\hline Cell structure & $\begin{array}{c}\text { Calculated } \\
\text { (this work) }\end{array}$ & $\begin{array}{c}\text { Observed } \\
\text { (Bish) [2] }\end{array}$ & $\begin{array}{c}\text { Observed } \\
\text { (Neder) [21] }\end{array}$ & $\begin{array}{c}\text { Observed } \\
\text { (Sato) [22] }\end{array}$ \\
\hline$a$ axis $(\AA)$ & 5.149 & 5.153 & 5.154 & 5.144 \\
$b$ axis $(\AA)$ & 8.934 & 8.941 & 8.942 & 8.924 \\
$c$ axis $(\AA)$ & 7.384 & 7.390 & 7.401 & 7.587 \\
$\alpha$ angle $(\mathrm{deg})$ & 91.93 & 91.92 & 91.69 & 91.08 \\
$\beta$ angle $(\mathrm{deg})$ & 105.0420 & 105.046 & 104.61 & 104.60 \\
$\gamma$ angle $(\mathrm{deg})$ & 89.9710 & 89.79 & 89.82 & 89.86 \\
$\rho\left(\mathrm{g} / \mathrm{cm}^{3}\right)$ & 2.668652 & - & 2.599 & 2.544 \\
\hline
\end{tabular}

Table 3. Calculated elastic constant.

\begin{tabular}{cccc}
\hline Elastic constant & Sato [22] & Militizer $[14]$ & This work \\
\hline C11 & $178.5 \pm 8.8$ & 169.1 & 209.0343 \\
C22 & $200.9 \pm 12.8$ & 179.7 & 209.6761 \\
C33 & $32.1 \pm 2.0$ & 81.1 & 68.4720 \\
C44 & $11.2 \pm 5.6$ & 17.0 & 12.4953 \\
C55 & $22.2 \pm 1.4$ & 26.6 & 6.7199 \\
C66 & $60.1 \pm 3.2$ & 57.6 & 50.1239 \\
C12 & $71.5 \pm 7.1$ & 66.1 & 126.0545 \\
C13 & $2.0 \pm 5.3$ & 15.4 & 16.8481 \\
C14 & $-0.4 \pm 2.1$ & -0.4 & 2.9326 \\
C15 & $-41.7 \pm 1.4$ & -34.0 & -0.9305 \\
C16 & $-2.3 \pm 1.7$ & -7.8 & -3.6306 \\
C23 & $-2.9 \pm 5.7$ & 10.2 & 19.1547 \\
C24 & $-2.8 \pm 2.7$ & -3.4 & 1.6428 \\
C25 & $-19.8 \pm 0.6$ & -16.1 & 0.0802 \\
C26 & $1.9 \pm 1.5$ & -0.1 & 9.0795 \\
C34 & $-0.2 \pm 1.4$ & -2.9 & -2.3010 \\
C35 & $1.7 \pm 1.8$ & 6.7 & -2.9557 \\
C36 & $3.4 \pm 2.2$ & -0.1 & -0.7526 \\
C45 & $-1.2 \pm 1.2$ & -0.7 & -0.0226 \\
C46 & $-12.9 \pm 2.4$ & -12.4 & 2.2793 \\
C56 & $0.8 \pm 0.7$ & 1.1 & 3.6822 \\
\hline
\end{tabular}

The calculated elastic constant tensors indicate that the $a$ direction is slightly more flexible than the $b$ direction. The calculated elastic constant tensor along $c$ is much 
lower than the constants calculated along $a$ and $b$ consistent with the crystal structure of kaolinite [22].

\section{Conclusions}

In summary, these calculations have shown that the computational techniques are a useful tool for investigating clay structures and mechanical properties. Predicting the mechanical properties of minerals that are difficult to obtain experimentally because of their small particle size (typically $<2$ micrometers).

\section{Acknowledgements}

Dr KARMOUS Mohamed Salah is grateful to Dr David $S$ Coombes for his helpful discussion. Dr Julian Gale (Imperial College, University of London) is also gratefully acknowledged for providing GULP and for useful discussions.

\section{References}

[1] R. A. Young and A. W. Hewat, "Verification of the Triclinic Crystal Structure of Kaolinite," Clays and Clay Minerals, Vol. 36, No. 3, 1988, pp. 225-232. doi:10.1346/CCMN.1988.0360303

[2] D. L. Bish, and C. T. Johnston, "Rietveld Refinement and Fourier Transform Infrared Spectroscopic Study of the Dickite Structure at Low Temperature," Clays and Clay Minerals, Vol. 41, No. 31, 1993, pp. 297-304. doi:10.1346/CCMN.1993.0410304

[3] S. Naamen, H. B. Rhaiem, M. S. Karmous and A. B. H. Amara, "XRD Study of the Stacking Mode of the Nacrite/Alkali Halides Complexes," Zeitschrift fur Kristallographie, Vol. 23, No. 2, 2006, pp. 499-504

[4] M. S. Karmous, J. Samira, J.-L. Robert and A. B. H. Amara, "Nature of Disorder in Synthetic Hectorite," Applied Clay Science, Vol. 51, No. 1-2, 2011, pp. 23-32. doi:10.1016/j.clay.2010.10.018

[5] T. Vanorio, M. Prasad and A. Nur, "Elastic Properties of Dry Clay Mineral Aggregates, Suspensions and Sandstones," Geophysical Journal International, Vol. 155, No. 1, 2003, pp. 319-326. doi:10.1046/j.1365-246X.2003.02046.X

[6] K. S. Alexandrov and T. V. Ryzhova, "Elastic Properties of Rock-Forming Minerals II. Layered Silicates,” Bulletin. USSR Academy of Science, Geophysics, Vol. 9, No. , 1961, pp. 165-1168.

[7] P. A. Berge and J. G. Berryman, "Realizability of Negative Pore Compressibility in Poroelastic Composites," Journal of Applied Mechanics, Vol. 62, No. 4, 1995, pp. 1053-1062. doi:10.1115/1.2896042

[8] K. W. Katahara, “Clay Mineral Elastic Properties,” SEG Annual Meeting Expanded Technical Programme Ab- stracts, 1996.

[9] Z. Wang, H. Wang and M. E. Cates, "Effective Elastic Properties of Solid Clays,” Geophysics, Vol. 66, No. 2, 2001, pp. 428-440. doi:10.1190/1.1444934

[10] C. Tosaya and A. Nur, "Effects of Diagenesis and Clays on Compressional Velocities in Rocks," Geophysical Research Letters, Vol. 9, No. 1, 1982, pp. 5-8. doi:10.1029/GL009i001p00005

[11] J. P. Castagna, D.-H. Han and M. L. Batzle, "Issues in Rock Physics and Implications for DHI Interpretation," The Leading Edge, Vol. 14, No. , 1995, pp. 883-885. doi:10.1190/1.1437178

[12] D. H. Han, A. Nur and D. Morgan, "Effects of Porosity and Clay Content on Wave Velocities in Sandstones," Geophysics, Vol. 51, No. 11, 1986, pp. 2093-2107. doi:10.1190/1.1442062

[13] S. Jemai, A. B. H. Amara, J. B. Brahim and A. Plançon, "Structural Study of a $10 \AA$ Anstable Hydrate of Kaolinite,” Journal of Applied Crystallography, Vol. 33, No. 4, 2000, pp. 1075-1081. doi:10.1107/S0021889800004878

[14] B. Militzer, H.-R. Wenk, S. Stackhouse and L. Stixrude, "First-Principles Calculation of the Elastic Moduli of Sheet Silicates and Their Application to Shale Anisotropy,” American Mineralogist, Vol. 96, No. , 2011, pp 125137. doi:10.2138/am.2011.3558

[15] J. D. Gale, "GULP: A Computer Program for the Symmetry-Adapted Simulation of Solids," Journal of the Chemical Society - Faraday Transactions, Vol. 93, No. 4, 1997, pp. 629-637. doi:10.1039/a606455h

[16] B. G. Dick and A. W. Overhauser, "Theory of the Dielectric Constants of Alkali Halide Crystals," Physical Review, Vol. 112, No. 1, 1958, pp. 90-103. doi:10.1103/PhysRev.112.90

[17] K.-P. Schröder, J. Sauer, M. Leslie, C. Richard, A. Catlow and J. M. Thomas, "Bridging Hydrodyl Groups in Zeolitic Catalysts: A Computer Simulation of Their Structure, Vibrational Properties and Acidity in Protonated Faujasites (HY Zeolites)," Chemical Physics Letters, Vol. 188, No. 3-4, 1992, pp. 320-325. doi:10.1016/0009-2614(92)90030-Q

[18] D. R. Collins and C. R. A Catlow, "Computer Simulation of Structures and Cohesive Properties of Micas," American Mineralogist, Vol.77, No. 11-12, 1992, pp. 11721181.

[19] D. S. Coombes, C. R. A. Catlow and J. M. Garcés, "Computational Studies of Layered Silicates," Modelling and Simulation in Materials Science and Engineering, Vol. 11, No. 3, 2003, pp. 301-306. doi:10.1088/0965-0393/11/3/303

[20] P. H. J. Mercier and Y. Le Page, "Kaolin Polytypes Revisited Abinitio,” Acta Crystallographica, Vol. 64, No. , 2008, pp. 131-143. doi:10.1107/S0108768108001924

[21] R. B. Neder, M. Burghammer, T. Z. Grasl, H. Schulz, A. Bram and S. Fiedler, "Refinement of the Kaolinite Structure from Single-Crystal Synchrotron Data," Clays and Clay Minerals, Vol.47, No. , 1999, pp. 487-494. doi:10.1346/CCMN.1999.0470411 
[22] H. Sato, K. Ono, C. T. Johnston and A. Yamagishi, "First-Principles Studies on Elastic Constants of a 1:1 Layered Kaolinite Mineral,” American Mineralogist, Vol.
90, No. , 2005, pp. 1824-1826. doi:10.2138/am.2005.1832 